\title{
Preparation and characterization of anticorrosion polyurethane paints and coatings based on novel Zn-free phosphates
}

\author{
Krzysztof Kowalczyk, Kinga Euczka, \\ Barbara Grzmil
}

(C) The Author(s) 2014. This article is published with open access at Springerlink.com

\begin{abstract}
Novel aluminum ammonium phosphates (AAP) were tested as anticorrosion fillers in twocomponent solventborne polyurethane paints. Their properties were compared with microsized aluminum zinc phosphate (AZP) as well as with nanosized (nAP) and microsized (AP) aluminum phosphates. Generally, coating compositions containing AAP exhibited similar or slightly higher viscosity than the systems with AZP and AP. Moreover, cured polyurethane coats with AAP reached higher gloss and better adhesion to a steel substrate. The results of salt spray tests $(2500 \mathrm{~h})$ showed that anticorrosive properties of coats containing $10 \mathrm{wt} \%$ of AAP were similar or better than those noted for coats with $15.6 \mathrm{wt} \%$ of AZP or $13.7 \mathrm{wt} \%$ of AP. Electrochemical impedance spectroscopic tests revealed markedly higher barrier properties of coats with AAP in comparison to an AP-based sample.
\end{abstract}

Keywords Aluminum ammonium phosphate, Aluminum zinc phosphate, Aluminum phosphate, Anticorrosion paint, Polyurethane paint

\section{Introduction}

Red lead and zinc chromate (VI) belong to the most effective anticorrosion microfillers in protective paints; however, because of their high toxicity, they are

\footnotetext{
K. Kowalczyk $(\bowtie)$

Polymer Institute, West Pomeranian University of Technology in Szczecin, ul. Pułaskiego 10, 70-322 Szczecin, Poland

e-mail: kkowalczyk@zut.edu.pl

K. Łuczka, B. Grzmil

Institute of Chemical and Environment Engineering,

West Pomeranian University of Technology in Szczecin, ul.

Pułaskiego 10, 70-322 Szczecin, Poland
}

banned by law in many countries. Thus, solventborne, low-VOC, and water-thinnable coating compositions are usually filled with borates (i.e., zinc borate, barium metaborate), molybdates (basic zinc molybdate, basic calcium zinc molybdate), calcium-exchange silica, or phosphites as well as with various types of phosphate powders. ${ }^{1-3}$ Phosphomolybdates, phosphovanadates, phosphosilicates, phosphates, and hydroxyphosphates of $\mathrm{Al}, \mathrm{Ca}, \mathrm{Fe}$ (III), $\mathrm{Ba}$, and/or $\mathrm{Mg}$ were successfully applied in anticorrosion coats, ${ }^{1,4,5}$ but the best rust inhibiting properties were observed for paints with zinc-based phosphates. ${ }^{1,6-9}$ Nevertheless, a few papers reported a detrimental influence of zinc phosphate on the natural environment ${ }^{10}$, and paints containing that filler have to be labeled as very toxic to aquatic life (pictogram GHS09). Therefore intensive research on chemical modification of the mentioned microfiller (mainly by incorporation of $\mathrm{Al}, \mathrm{Ca}$, and/or $\mathrm{Fe}$ ) as well as tests of the novel zinc-free phosphates are in progress. Relatively high efficiency of aluminum zinc phosphates (AZPs) in anticorrosion paints based on epoxy, epoxyester, or acrylic binders was presented in publications. ${ }^{411-15}$ Comparison of protective features of $2 \mathrm{~K}$ polyurethane paints containing microsized AZP or nanosized aluminum phosphate (AP) was published as well. ${ }^{16}$ In some cases the polyurethane paints with the latter type of phosphate reached higher anticorrosive properties (e.g., higher blistering resistance) than similar coats containing AZP. Nevertheless, solventborne paints filled with nanosized AP exhibited higher viscosity and lower adhesion (after curing) to a steel substrate than similar compositions based on a microsized AZP. ${ }^{16,17}$

In this work, novel $\mathrm{Zn}$-free phosphate fillers were presented and characterized. They were obtained via reaction of aluminum sulfate and ammonium phosphate in an aqueous medium and applied as an anticorrosion component in a $2 \mathrm{~K}$ solventborne polyurethane paint. Prepared coating compositions and 
coats have been compared to the systems based on a commercial microsized AZP, commercial microsized AP, or nanosized APs. The $\Lambda$ parameter value (i.e., pigment volume concentration (PVC)/critical pigment volume concentration $(\mathrm{CPVC})=0.55)$ for prepared coating systems was applied according to the literature data. ${ }^{8}$

\section{Materials and methods}

\section{Commercial materials}

The following commercial components have been used for solventborne $2 \mathrm{~K}$ polyurethane paint preparation:

- WorléeCryl A2218, 50\% solution of hydroxyacrylic resin in xylene/butyl acetate mixture, viscosity ca. $1250 \mathrm{mPa} \cdot \mathrm{s}$ at $20^{\circ} \mathrm{C}$, hydroxyl value $58 \mathrm{mg} \mathrm{KOH} / \mathrm{g}$ (on solids) (Worlée-Chemie GmbH, Germany);

- Tolonate HDB-LV, hexamethylene diisocyanate derivative, viscosity ca. $2000 \mathrm{mPa} \cdot \mathrm{s}$ at $25^{\circ} \mathrm{C}, \mathrm{NCO}$ content $23.5 \mathrm{wt} \%$ (Perstorp AB, Sweden);

- AZP (FAC, Złoty Stok Farby, Poland) and AP (Rima-Cor ZFM, Gustav Grolman GmbH, Germany) as reference anticorrosion fillers;

- Mica/quartz mixture, specific gravity $2.75 \mathrm{~g} / \mathrm{cm}^{3}$, oil absorption $35 \mathrm{~g} / 100 \mathrm{~g}$ (Aspolit F40, Aspanger Bergbau \& Mineralwerke GmbH, Austria);

- Titanium dioxide $\left(\mathrm{TiO}_{2}\right)$, specific gravity $4.1 \mathrm{~g} / \mathrm{cm}^{3}$, oil absorption $21 \mathrm{~g} / 100 \mathrm{~g}$ (Tytanpol R001, Z.Ch. Police S.A., Poland);

- Wollastonite treated with alkylsilane, specific gravity $2.85 \mathrm{~g} / \mathrm{cm}^{3}$, oil absorption $40 \mathrm{~g} / 100 \mathrm{~g}$ (Tremin 939300 FST, Quarzwerke GmbH, Germany);

- Talc, specific gravity $2.75 \mathrm{~g} / \mathrm{cm}^{3}$, oil absorption $49 \mathrm{~g} /$ $100 \mathrm{~g}$ (Finntalc M03-SQ, Mondo Minerals OY, Finland);

- Xylene (90 wt\%) and butyl acetate (10 wt\%) mixture as a solvent (POCh S.A., Poland);

- Wetting/dispersing additive based on unsaturated polycarboxylic acid polymer (BYK-P 104S, BYKChemie GmbH, Germany);

- Silicone defoamer (BYK-067A, BYK-Chemie $\mathrm{GmbH})$.

\section{Phosphate fillers preparation}

\section{Nanosized aluminum phosphate preparation}

Nanosized aluminum phosphates (nAPs) were prepared via reaction of aluminum sulfate $(\geq 99 \%$,
ChemPur, Poland) and diammonium phosphate ( $\geq 99 \%$, POCh, Poland) (molar ratio $\mathrm{Al}: \mathrm{PO}_{4}{ }^{3-} 1: 1$ ) in an aqueous solution $(\mathrm{pH} 4.1)$ at $20^{\circ} \mathrm{C}$. The precipitation process was performed in a glass reactor equipped with a mechanical stirrer. The system was configured to measure and control $\mathrm{pH}$ value, temperature, and agitation speed. Aluminum sulfate solution (30 wt \%) was added to agitated diammonium phosphate solution (30 wt \%) and stirred for $0.5 \mathrm{~h}$. Precipitated product was washed three times using distilled water and dried for $3 \mathrm{~h}$ at $105^{\circ} \mathrm{C}$ (amorphous AP, nAP-a) as well as for $1 \mathrm{~h}$ at $200^{\circ} \mathrm{C}$ in a muffle furnace (calcinated AP, nAP-c).

\section{Aluminum ammonium phosphate preparation}

Aluminum ammonium phosphates (AAPs) were prepared via reaction of aluminum sulfate $(\geq 99 \%$, ChemPur, Poland) and ammonium phosphates $(\geq 99 \%$, $\mathrm{POCh}$, Poland) in an aqueous solution at $23^{\circ} \mathrm{C}$. Aluminum sulfate solution was added to agitated ammonium phosphate solution and stirred for $0.5 \mathrm{~h}$. The $\mathrm{pH}$ value of the reaction medium was in the range from $\mathrm{pH} 4$ to $\mathrm{pH} 8$ and it was adjusted using ammonia water. Precipitated product was washed three times in distilled water and dried for $3 \mathrm{~h}$ at $70^{\circ} \mathrm{C}$. The parameters of the AAP preparation process are summarized in Table 1.

\section{Paints preparation}

A phosphate filler and extenders were dispersed $\left(45 \mathrm{~min}, 25^{\circ} \mathrm{C}\right)$ in a part of a hydroxyacrylic resin containing auxiliary additives and solvent in a pearlmill (Klaxon, UK) filled with glass pearls (Ø2.3$2.6 \mathrm{~mm}$ ). Then, the paste was mixed (for $1 \mathrm{~h}$ ) with the rest of the hydroxyacrylic component using a laboratory dissolver with a heavy-duty dispersion impeller (VMA Getzmann GmbH, Germany) at $1250 \mathrm{rpm}$. The prepared paint component was filtered $(190 \mu \mathrm{m})$ and mixed with diisocyanate hardener using a laboratory mixer. The paint components, phosphate fillers content, PVC, and CPVC values are specified in Table 2. Coating compositions filled with commercial microsized AZP and AP were abbreviated to PU/AZP and PU/AP, while paints based on nAPs and AAPs were noted as PU/nAP (i.e., PU/nAP-a, PU/nAP-c) and PU/ AAP, respectively.

\section{Samples preparation}

The paints were applied with a brush (according to the Polish Standard PN-C-81514:1979) and leveled with a spiral film applicator (150 $\mu \mathrm{m}$, Unicoater 409, Erichsen $\mathrm{GmbH}$, Germany) onto a steel substrate. The steel panels (Q-Panel, Q-Lab Europe, England) with dimensions of $76 \times 152 \mathrm{~mm}$ [for adhesion and 
Table 1: Aluminum ammonium phosphates preparation parameters

\begin{tabular}{llllll} 
Phosphate acronym & \multicolumn{1}{c}{ AAP1 } & \multicolumn{1}{c}{ AAP2 } & \multicolumn{1}{c}{ AAP3 } & AAP4 \\
\hline Ammonium phosphate type & $\left(\mathrm{NH}_{4}\right)_{3} \mathrm{PO}_{4}$ & $\left(\mathrm{NH}_{4}\right)_{2} \mathrm{HPO}_{4}$ & $\mathrm{NH}_{4} \mathrm{H}_{2} \mathrm{PO}_{4}$ & $\left(\mathrm{NH}_{4}\right)_{2} \mathrm{HPO}_{4}$ & $\mathrm{NH}_{4} \mathrm{H}_{2} \mathrm{PO}_{4}$ \\
Molar ratio of $\mathrm{Al}^{3+}: \mathrm{NH}_{4}{ }^{+}: \mathrm{PO}_{4}{ }^{3-}$ & $0.66: 3: 1$ & $0.66: 2: 1$ & $0.66: 1: 1$ & $0.66: 2: 1$ & $0.66: 1: 1$ \\
Salt concentration $(w \mathrm{w} \%)$ & 40 & 50 & 40 & 30 & 40 \\
Solution pH & 6 & 8 & 4 & 8 & 8 \\
\hline
\end{tabular}

Table 2: Coating composition

\begin{tabular}{|c|c|c|c|c|c|c|c|c|c|}
\hline $\begin{array}{l}\text { Paint acronym } \\
\text { Phosphate acronym } \\
\text { Phosphate type }\end{array}$ & $\begin{array}{c}\text { PU/AZP } \\
\text { AZP } \\
\text { Aluminum zinc } \\
\text { phosphate }\end{array}$ & $\begin{array}{l}\text { PU/AP } \\
\text { AP All }\end{array}$ & $\begin{array}{l}\mathrm{PU} / \mathrm{nAP}-\mathrm{a} \\
\text { nAP-a } \\
\text { minum pho }\end{array}$ & $\begin{array}{l}\mathrm{PU} / \mathrm{nAP}-\mathrm{c} \\
\text { nAP-c } \\
\text { sphate }\end{array}$ & $\begin{array}{l}\text { PU/AAP1 } \\
\text { AAP1 } \\
\text { Alum }\end{array}$ & $\begin{array}{l}\text { PU/AAP2 } \\
\text { AAP2 } \\
\text { inum ammc }\end{array}$ & $\begin{array}{l}\text { PU/AAP3 } \\
\text { AAP3 } \\
\text { onium phos }\end{array}$ & $\begin{array}{l}\text { PU/AAP4 } \\
\text { AAP4 } \\
\text { phate }\end{array}$ & $\begin{array}{l}\text { PU/AAP5 } \\
\text { AAP5 }\end{array}$ \\
\hline \multicolumn{10}{|c|}{ Pigment volume content (vol\%) } \\
\hline Mica/quartz & 35 & & & & & & & & \\
\hline $\mathrm{TiO}_{2}$ & 15 & & & & & & & & \\
\hline Wollastonite & 10 & & & & & & & & \\
\hline Talc & 10 & & & & & & & & \\
\hline Phosphate & 30 & & & & & & & & \\
\hline $\begin{array}{l}\text { Phosphate content }{ }^{a} \\
\quad(w t \%)\end{array}$ & 15.6 & 13.7 & 10.6 & 9.8 & 9.5 & 9.6 & 10.3 & 9.9 & 10.0 \\
\hline $\begin{array}{l}\text { Phosphate content }{ }^{\mathrm{a}} \\
\quad(\mathrm{vol} \%)\end{array}$ & 7.7 & 7.6 & 5.1 & 5.4 & 6.6 & 6.8 & 7.0 & 6.7 & 7.1 \\
\hline PVC & 25.7 & 25.5 & 17.0 & 18.2 & 21.8 & 22.6 & 23.4 & 22.2 & 23.6 \\
\hline CPVC & 46.7 & 46.3 & 30.8 & 33.0 & 39.7 & 41.1 & 42.5 & 40.4 & 42.9 \\
\hline$\Lambda$ & 0.55 & & & & & & & & \\
\hline
\end{tabular}

a Phosphate content in a cured coat

electrochemical impedance spectroscopy (EIS) analysis] and $102 \times 152 \mathrm{~mm}$ (salt spray test) were used. The two-layer samples for EIS tests, as well as for salt spray tests, were prepared by applying two layers of coating compositions with $24 \mathrm{~h}$ painting intervals. The paints were also applied onto glass plates (for hardness measurements) using a gap applicator $(300 \mu \mathrm{m})$. The coats were cured for 14 days at room temperature before testing.

\section{Test methods}

\section{Characterization of phosphate pigments}

The specific gravity of APs and AAPs was measured using a pycnometric method (glass pycnometer $25 \mathrm{~cm}^{3}$ filled with propan-2-ol). The oil absorption for mentioned phosphates was measured according to the Polish standard PN-EN ISO 787-5. The Brunauer-EmmettTeller surface area $\left(S_{\mathrm{BET}}\right)$ measurements were conducted using Micrometrics Quadrasorb SI (Quantachrome Instrument). The $\mathrm{N}_{2}$ adsorption/desorption tests were carried out at $-196^{\circ} \mathrm{C}$. The particle size of phosphate fillers dispersed in di- $n$-butyl phthalate by sonication (25 min, UPS400S, Hielscher Ultrasonics $\mathrm{GmbH}$, Germany) was analyzed using light scattering technique (LST) (Zetasizer Nano, Malvern, UK). The solubility of phosphates in distilled water at room temperature was determined. The conductivity of the aqueous phosphate dispersion (5 wt \%) was tested using an Elmetron CC-505 conductometer (Elmetron, Poland). The $\mathrm{pH}$ of an aqueous suspension (10 wt \%) of micro- and nanofillers was examined according to the PN-EN ISO 787-9-2000 standard. The chemical composition of tested nanofillers was determined by the colorimetric vanadium-molybdenum method $\left(\mathrm{P}_{2} \mathrm{O}_{5}\right.$ content), complexometric test with EDTA (aluminum content $)^{19}$ as well as using ion selective electrode Orion 11-35 (ammonium content). ${ }^{20}$ SEM images of AP (nAPa) and AAP (AAP5) were obtained using scanning electron microscopes (DSM 962, Zeiss, and SU-70 Hitachi, respectively).

Tafel experiments $( \pm 250 \mathrm{mV}$ in relation to OCP, scan rate $0.25 \mathrm{mV} / \mathrm{s}$ ) for an uncoated steel substrate (Q-Panels) were performed using DC105 software and FAS2 femtostat (Gamry, USA). As a result, corrosion potential $\left(E_{\text {corr }}\right)$, corrosion current density $\left(i_{\text {corr }}\right)$, and 
corrosion rate $(P)$ values were determined by means of Echem Analyst software (Gamry). Steel polarization was carried out using electrolytes prepared by shaking a phosphate filler $(2.5 \mathrm{~g})$ with $100 \mathrm{~g}$ of $3.5 \mathrm{wt} \% \mathrm{NaCl}$ aqueous solution for $2 \mathrm{~h}$ (i.e., twice for $1 \mathrm{~h}$ with a $22-\mathrm{h}$ interval). Then the suspension was centrifuged (4000 rpm, $10 \mathrm{~min}$ ) and an aqueous extract was carefully decanted. The Tafel tests were performed after $20 \mathrm{~h}$ of a glass cell filling with phosphate extract with neutral $\mathrm{pH}$ or $\mathrm{pH}=9$ (adjusted by means of $0.25 \mathrm{M}$ $\mathrm{NaOH}$ aqueous solution). The corrosion inhibition efficiency $(\eta, \%)$ of phosphate extracts was calculated according to the following equation:

$\eta=\left[\frac{i_{0}-i}{i_{0}}\right] \times 100$

where $i_{0}$ and $i$ are corrosion current densities registered for steel substrate immersed in $3.5 \mathrm{wt} \% \mathrm{NaCl}$ aqueous solution and an aqueous extract of phosphate filler, respectively.

\section{Characterization of coating compositions and cured paints}

High shear viscosity tests (I.C.I. cone-plate system, Research Equipment Ltd., England) were performed for ready-to-use liquid coating compositions. The pendulum hardness (PN-EN ISO 1522:2008, König pendulum; three measurements for each sample), pull-off adhesion (PN-EN ISO 4624:2004, PHO-4 hydraulic apparatus, Dozafil, Poland; 10 measurements for each composition), and gloss (PN-EN ISO 2813, 60 ${ }^{\circ}$, MicroTri-Gloss, BYK-Gardner GmbH, Germany) were evaluated on cured paints. The thickness of cured films was measured with the electronic film gauge Byko-test 8500 (BYK-Gardner) according to PN-EN ISO 2808. EIS tests were carried out with coated panels (two-layer coatings with 160-178 $\mu$ m thickness) after $0,500,1000$, and $2500 \mathrm{~h}$ of immersion in a periodically air-saturated aqueous $\mathrm{NaCl}$ solution $(3.5 \mathrm{wt} \%)$. These measurements were realized using three coated samples for each tested composition. A three-electrode glass cell (with $14.5 \mathrm{~cm}^{2}$ surface sample area) equipped with a graphite counter electrode and a saturated calomel reference electrode was used inside the Faraday cage. The impedance data (at frequency $0.001-10,000 \mathrm{~Hz}, 100 \mathrm{mV}$ amplitude of sinusoidal voltage vs OCP) was collected using EIS300 software with FAS2 femtostat (Gamry) and analyzed using the electric circuit models presented in Fig. 1 ( $R_{\mathrm{u}}$-uncompensated solution resistance, $R_{\mathrm{p}}$-pore resistance, $R_{\mathrm{f}}$-polarization resistance, $C_{\mathrm{c}}$-coating capacitance, $C_{\mathrm{f}}$-double layer capacitance). ${ }^{21}$ The pore resistance, polarization resistance, and coating capacitance parameters were calculated with respect to the coat thickness and presented as relative $R_{\mathrm{p}}$ and $R_{\mathrm{f}}$ (i.e., $R_{\mathrm{pr}}$ and $\left.R_{\mathrm{fr}}, \Omega / \mu \mathrm{m}\right)$ and relative $C_{\mathrm{c}}\left(C_{\mathrm{cr}}, \mathrm{F} / \mu \mathrm{m}\right)$ with a standard deviation.
The salt spray test was carried out according to PNEN ISO 9227:2007 in CorrosionBox 400 (Co.fo.me.gra., Italy) using an aqueous $\mathrm{NaCl}$ solution (concentration of $50 \pm 5 \mathrm{~g} / \mathrm{L}$ ) sprayed with compressed oilfree air. The back side and edges of steel panels with $\mathrm{x}$ cut coats (according to EN ISO 17872:2007) were protected with a special pressure adhesive tape (TESA Tape, USA) and mounted at an angle of $20^{\circ}$ vertically. The temperature in a spray cabinet was maintained at $35^{\circ} \mathrm{C}$.

\section{Results and discussion}

\section{Phosphate fillers}

The physical and chemical properties of the tested phosphate fillers are collected in Table 3. As can be seen, most AAP fillers exhibited significantly higher surface area values (e.g., $240.9 \mathrm{~m}^{2} / \mathrm{g}$ for AAP5) and relatively lower oil absorption values $(82 \mathrm{~g} / 100 \mathrm{~g})$ in comparison to nAPs $\left(81.9-98.8 \mathrm{~m}^{2} / \mathrm{g}\right.$ and $151-153 \mathrm{~g}$ of oil/100 g, respectively). Moreover, particle size values measured using an LST were markedly higher for AAP $(500-990 \mathrm{~nm})$ than for nAP fillers $(270 \mathrm{~nm})$. Nevertheless, SEM images of AAP5 and nAP-a revealed that the former was significantly more fine-grained; the particle size was in the range of ca. 40 to $145 \mathrm{~nm}$ (Fig. 2). Taking into consideration the fact that particle diameter values of nAP-a (digitally measured by means of SEM image; $140-310 \mathrm{~nm}$ ) correlated with the result obtained by using LST, it can be found that AAP particles were not efficiently dispersed in butyl phthalate after sonication and large agglomerates of AAP were detected by LST (Table 3). Probably, low oil absorption values of AAP (in comparison to nAP fillers) were also affected by agglomerates present in
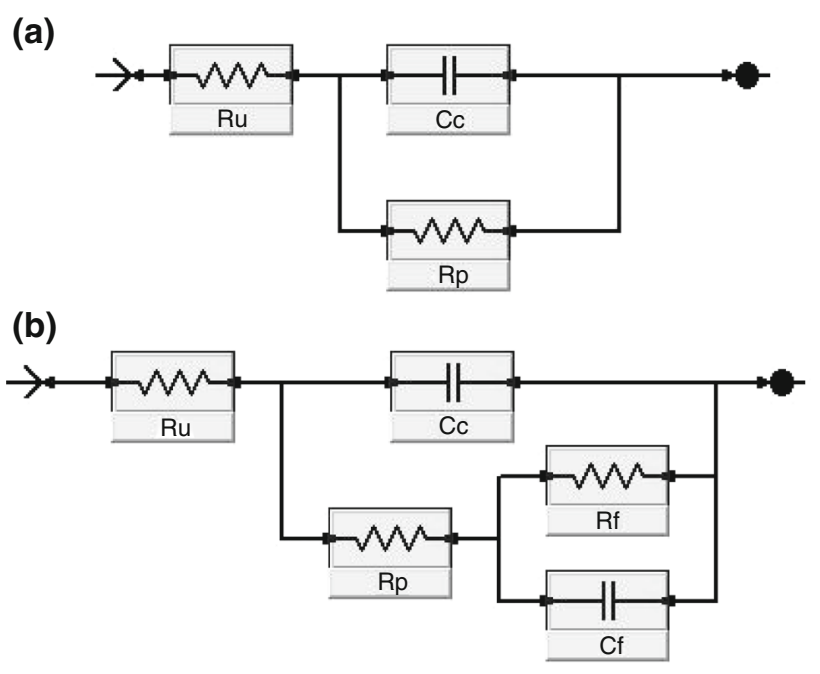

Fig. 1: Electric circuit models for coats (a) before immersion and (b) after immersion in an aqueous $\mathrm{NaCl}$ solution 
Table 3: Physical and chemical properties of tested phosphate fillers

\begin{tabular}{|c|c|c|c|c|c|c|c|c|c|}
\hline \multirow{2}{*}{$\begin{array}{l}\text { Phosphate filler } \\
\text { Phosphate acronym }\end{array}$} & \multirow{2}{*}{$\begin{array}{l}\text { Aluminum zinc phosphate } \\
\qquad \text { AZP }\end{array}$} & \multicolumn{3}{|c|}{ Aluminum phosphate } & \multicolumn{5}{|c|}{ Aluminum ammonium phosphate } \\
\hline & & AP & nAP-a & $n A P-c^{b}$ & AAP1 & AAP2 & AAP3 & AAP4 & AAP5 \\
\hline Specific density $\left(\mathrm{g} / \mathrm{cm}^{3}\right)$ & $3.3^{\mathrm{d}}$ & 2.85 & 2.99 & 2.59 & 2.15 & 2.1 & 2.21 & 2.2 & 2.1 \\
\hline Oil absorption ( $\mathrm{g} / 100 \mathrm{~g})$ & $35^{d}$ & 43 & 153 & 151 & 108 & 98 & 82 & 99 & 82 \\
\hline$S_{\mathrm{BET}}\left(\mathrm{m}^{2} / \mathrm{g}\right)$ & 5.8 & 4.2 & 98.8 & 81.9 & 68.2 & 101.0 & 107.7 & 206.0 & 240.9 \\
\hline Particle size $(\mu \mathrm{m})$ & $\leq 63^{d}$ & $<4^{d}$ & 0.27 & 0.27 & 0.7 & 0.61 & 0.5 & 0.99 & 0.62 \\
\hline Water solubility (wt\%) & $\leq 0.8^{\mathrm{d}}$ & $\leq 1.0$ & $\leq 0.23$ & $\leq 0.23$ & $\leq 0.32$ & $\leq 0.32$ & $\leq 0.47$ & $\leq 0.53$ & 0.31 \\
\hline Conductivity $^{\mathrm{c}}(\mu \mathrm{S} / \mathrm{cm})$ & 24 & 1606 & 341 & 546 & 1520 & 1854 & 631 & 1840 & 2169 \\
\hline $\mathrm{pH}$ & 6.9 & 3.4 & 6.1 & 8.2 & 7.7 & 8.0 & 7.5 & 8.1 & 7.7 \\
\hline $\mathrm{P}_{2} \mathrm{O}_{5}$ content (wt\%) & 35.3 & $66^{d}$ & 37.9 & 50.2 & 21.2 & 22.6 & 13.2 & 18.3 & 26.4 \\
\hline Al content (wt\%) & 4.2 & $8^{d}$ & 16.1 & 19.2 & 12.2 & 12.7 & 10.0 & 8.1 & 12.6 \\
\hline $\mathrm{NH}_{3}$ content (wt\%) & 0 & 0 & 0 & 0 & 3.8 & 5.1 & 2.5 & 3.3 & 3.3 \\
\hline
\end{tabular}

\footnotetext{
a Contains 32.5 wt\% of $\mathrm{Zn}$

b See references $(16,17)$

c Conductivity of an aqueous extract of $5 \mathrm{wt} \%$ phosphate dispersion

d Manufacturer data
}
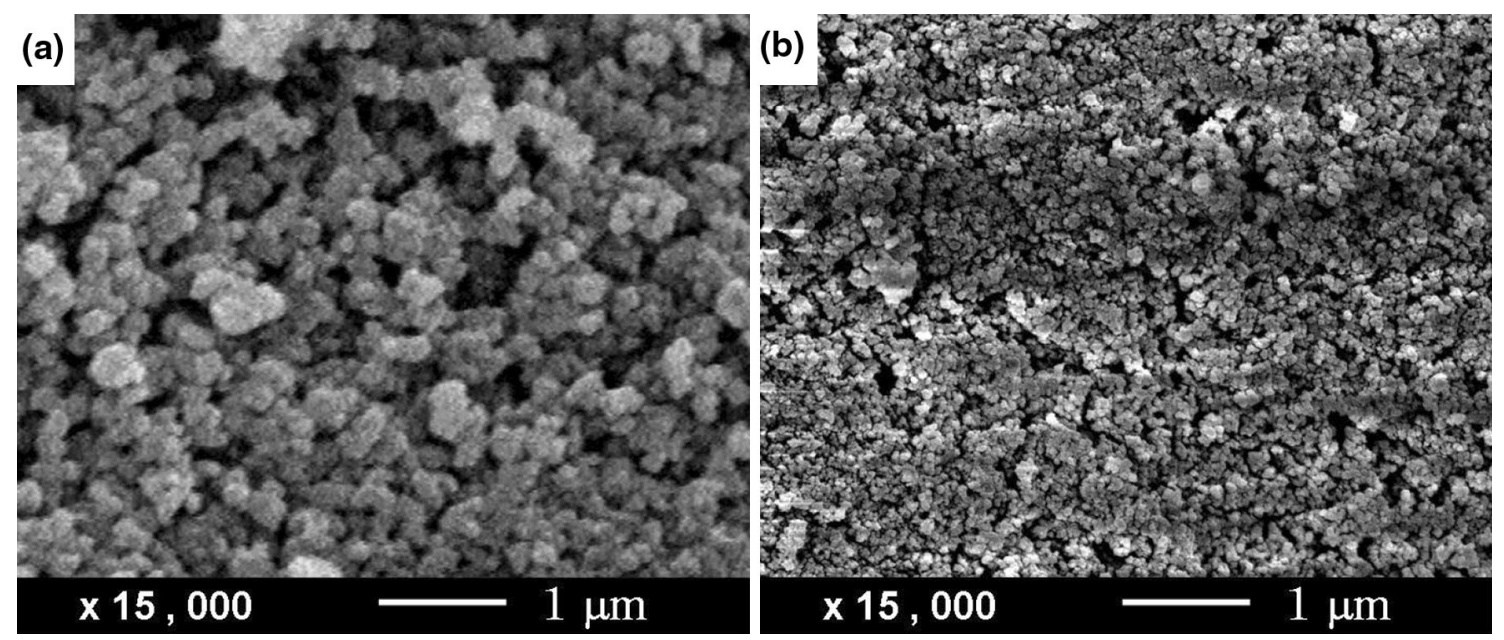

Fig. 2: SEM images of (a) amorphous aluminum phosphate (nAP-a) ${ }^{22}$ and (b) aluminum ammonium phosphate (AAP5)

the analyzed samples. It well explained the significant differences between oil absorption and $S_{\mathrm{BET}}$ values recorded for nAP and AAP fillers.

It is noteworthy that AAP fillers exhibited markedly higher water solubility $(0.31-0.53 \mathrm{wt} \%)$ and higher conductivity $(631-2169 \mu \mathrm{S} / \mathrm{cm}$ for aqueous extracts) than nAP $(0.23 \mathrm{wt} \%$ and $341-546 \mu \mathrm{S} / \mathrm{cm})$. On the other hand, AZP filler was characterized by higher water solubility $(0.8 \mathrm{wt} \%)$ and extremely low conductivity $(24 \mu \mathrm{S} / \mathrm{cm})$ in comparison to nAP and AAP fillers. The $\mathrm{pH}$ of AAP extracts (i.e., from 7.5 to 8.1 units of $\mathrm{pH})$ was higher than for AP $(\mathrm{pH}=3.4)$, amorphous nAP $(\mathrm{pH}=6.1)$ and AZP $(\mathrm{pH}=6.9)$ filler extracts. The AAP phosphates contained 13.2$26.4 \mathrm{wt} \%$ of $\mathrm{P}_{2} \mathrm{O}_{5}$ and $8.1-12.7 \mathrm{wt} \%$ of aluminum, while commercial AP consisted of $66 \mathrm{wt} \%$ of $\mathrm{P}_{2} \mathrm{O}_{5}$ and $8 \mathrm{wt} \%$ of $\mathrm{Al}$ (hence $\mathrm{pH}$ value for that filler was very low). The $\mathrm{NH}_{3}$ content in AAP was in the range of $2.5 \mathrm{wt} \%$ (AAP3) to $5.1 \mathrm{wt} \%$ (AAP2). Considering the AAP fillers prepared using the same molar ratios of components and either different solution concentration (AAP2 and AAP4; Table 1) or different $\mathrm{pH}$ values of the reaction medium (AAP3 and AAP5), it can be found that their compositions directly depended on the mentioned parameters. Moreover, the conductivity of aqueous AAP extracts was only affected by the $\mathrm{pH}$ of the reaction medium: conductivities of AAP2 and AAP4 were similar (1854$1840 \mu \mathrm{S} / \mathrm{cm}$ ), while that attribute value for AAP3 (i.e., $631 \mu \mathrm{S} / \mathrm{cm}$ ) was significantly lower than for AAP5 extract $(2169 \mu \mathrm{S} / \mathrm{cm})$. It should be mentioned that AAP3 contained only $2.5 \mathrm{wt} \%$ of $\mathrm{NH}_{3}$ but electrical conductivity did not directly correlate to that parameter value. 
The polarization curves for the steel immersed in an aqueous $\mathrm{NaCl}$ solution as well as in selected extracts of phosphate in an aqueous $\mathrm{NaCl}$ solution are shown in Fig. 3a. The Tafel test results, i.e., corrosion potential $\left(E_{\text {corr }}\right)$, corrosion current density $\left(i_{\text {corr }}\right)$, corrosion rate $(P)$, and corrosion inhibition efficiency $(\eta)$, are collected in Table 4. As can be observed, the corrosion potential values for steel tested in neutral extracts of AAPs, nAPs or AZP were similar (-725 and $-785 \mathrm{mV}$ for the AZP and nAP-a extracts, respectively) while $E_{\text {corr }}$ recorded for the AP extract was significantly shifted to the positive value $(-639 \mathrm{mV}$ vs SCE). Nevertheless, the corrosion current density $(104 \mu \mathrm{A} /$ $\mathrm{cm}^{2}$ ) as well as the corrosion rate of steel in the AP extract $(1200 \mu \mathrm{m} /$ year $)$ were catastrophically high. Probably, it was caused by relatively low $\mathrm{pH}$ of that extract-it is known that steel easily corrodes in similar conditions. ${ }^{23}$ Although $i_{\text {corr }}$ and $P$ values for steel immersed in extracts of nAP or AAP were low (in relation to AP extract), corrosion inhibition efficiency for these fillers was negative and reached $-75 \%$ for nAP-a and $-149 \%$ for AAP3-based electrolyte. On the other hand, corrosion inhibition efficiency calculated for AZP was relatively high, i.e., 49\% (Table 4); a significantly lower $\eta$ value for steel tested in aqueous
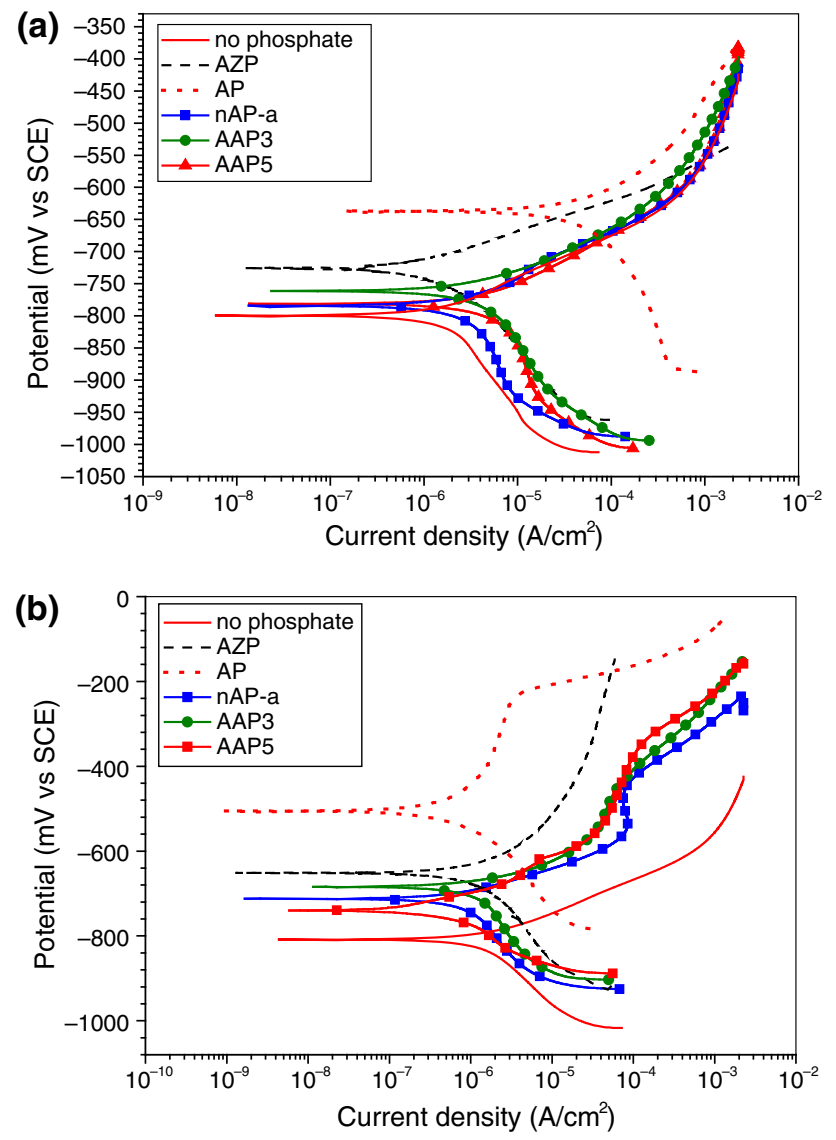

Fig. 3: Potentiodynamic polarization curves for steel immersed in (a) neutral and (b) basic extracts of AZP, AP, nAP-a, AAP3, and AAP5 in $3.5 \mathrm{wt} \% \mathrm{NaCl}$ aqueous solution extracts of phosphate containing $\mathrm{Al}$ and $\mathrm{Zn}$ was revealed by Bethencourt et al. (1\%). ${ }^{24}$ It should be noted that these fillers [AZP and that tested in reference (24)] were mainly based on $\mathrm{Zn}_{3}\left(\mathrm{PO}_{4}\right)_{2}$ exhibiting high anticorrosion efficiency. ${ }^{24}$ The corrosion rates of steel immersed in aqueous extracts of APs have not generally been presented and discussed in literature. However, anticorrosion efficiency of epoxy coatings containing the mentioned filler (measured during cyclic corrosion test) was ca. $93 \% .^{25}$ That parameter value for cold rolled steel polarized in an aqueous extract of aluminum triphosphate was $76 \%{ }^{26}$ Interestingly, in some cases studied "aluminum phosphates" contained markedly higher amount of $\mathrm{Zn}$ than Al. ${ }^{1}$

Polarization curves for steel immersed in neutral extracts of nAP-a and AAP fillers (Fig. 3a) show different shapes for the cathodic branches in these electrolytes. Generally, the cathodic curves registered for AAP extracts were similar to that observed for AZP extract, while cathodic reactions on a steel substrate immersed in nAP-a extract proceeded at significantly reduced current density values. Therefore, the corrosion inhibition efficiency of nAPs (nAP-a, nAP-c) was higher than for AAP fillers (Table 4). In the case of AAP extracts it should be noted that the lowest corrosion rates were found for the fillers with the lowest $\mathrm{NH}_{3}$ content (i.e., AAP3, AAP4, and AAP 5; Table 3). The corrosive features of ammonium salt (e.g., fertilizers) are known and have been discussed in the literature. ${ }^{27}$

It is known that during a corrosion process in the presence of oxygen, $\mathrm{OH}^{-}$ions are generated and the $\mathrm{pH}$ value of electrolyte increases. In many cases, anticorrosion protection of steel substrate in a phosphate filler extract is affected by its $\mathrm{pH}$ value. The Tafel test results for steel immersed in a basic extract of AZP, AP, nAP, or AAP fillers in an aqueous $\mathrm{NaCl}$ solution are presented in Table 4 (polarization curves for steel immersed in selected extracts are shown in Fig. 3b). The corrosion potential value for steel immersed in an alkaline extract of AP was much higher $(-506 \mathrm{mV})$ than for steel in alkaline extracts of AZP $(-651 \mathrm{mV})$, nAPs $(-712 \mathrm{mV}$ for nAP-a and $698 \mathrm{mV}$ for $\mathrm{nAP}-\mathrm{c})$, or AAPs $(-609 \mathrm{mV}$ for AAP2 and $-738 \mathrm{mV}$ for AAP5). Although corrosion inhibition efficiency of the AP extract was markedly higher $(38 \%)$ in comparison to the AZP extract $(1 \%)$, much better anticorrosion properties were observed for the basic extract of AAP5 (74\%). High corrosion inhibition efficiency was also noted for the basic extracts of nAP-a $(37 \%$; similar result was noted for micro-sized AP), AAP4 (20\%), and AAP1 (19\%). In the case of AAP fillers, the $\eta$ values depended on $\mathrm{P}_{2} \mathrm{O}_{5}$ and $\mathrm{NH}_{3}$ content in the analyzed phosphates. The comparison of AAP1 and AAP2 (similar $\mathrm{P}_{2} \mathrm{O}_{5}$ and $\mathrm{Al}$ content, various $\mathrm{NH}_{3}$ content) showed that a lower amount of $\mathrm{NH}_{3}$ in AAP1 resulted in relatively high anticorrosion properties $(\eta=19 \%)$. On the other hand, a basic extract of AAP5 (26.4 wt \% of $\mathrm{P}_{2} \mathrm{O}_{5}, 3.3 \mathrm{wt} \%$ of 
Table 4: Tafel test results for a bare steel substrate immersed in aqueous extracts of phosphate fillers in 3.5 wt \% $\mathrm{NaCl}$ solution (neutral $\mathrm{pH}$ or $\mathrm{pH}=9$ )

\begin{tabular}{|c|c|c|c|c|c|c|c|c|}
\hline \multirow[t]{2}{*}{ Phosphate filler type } & \multicolumn{2}{|c|}{$E_{\text {corr }}$ (mV vs SCE) } & \multicolumn{2}{|c|}{$i_{\text {corr }}\left(\mu \mathrm{A} / \mathrm{cm}^{2}\right)$} & \multicolumn{2}{|c|}{$P(\mu \mathrm{m} /$ year $)$} & \multicolumn{2}{|c|}{$\eta(\%)$} \\
\hline & neutral $\mathrm{pH}$ & $\overline{\mathrm{pH}}=9$ & neutral pH & $\overline{\mathrm{pH}}=9$ & neutral $\mathrm{pH}$ & $\overline{\mathrm{pH}}=9$ & neutral $\mathrm{pH}$ & $\overline{\mathrm{pH}}=9$ \\
\hline AZP & -725 & -651 & 1.1 & 1.49 & 13 & 17 & 49 & 1 \\
\hline $\mathrm{AP}$ & -639 & -506 & 104 & 0.93 & 1200 & 10.8 & -4693 & 38 \\
\hline nAP-a & -785 & -712 & 3.8 & 0.94 & 44 & 11 & -75 & 37 \\
\hline nAP-c & -773 & -698 & 4.2 & 1.24 & 49 & 14.2 & -93 & 17 \\
\hline AAP1 & -771 & -623 & 13.9 & 1.21 & 161 & 14 & -540 & 19 \\
\hline AAP2 & -775 & -609 & 12.0 & 2.62 & 139 & 31 & -453 & -75 \\
\hline AAP3 & -761 & -684 & 5.4 & 1.44 & 63 & 16.8 & -149 & 4 \\
\hline AAP4 & -771 & -647 & 7.1 & 1.2 & 81 & 13.9 & -227 & 20 \\
\hline AAP5 & -778 & -738 & 6.9 & 0.39 & 80 & 4.6 & -218 & 74 \\
\hline
\end{tabular}

$\mathrm{NH}_{3}$ ) exhibited much higher $\eta$ value than an AAP1 extract $\left(21.2 \mathrm{wt} \%\right.$ of $\mathrm{P}_{2} \mathrm{O}_{5}$ and $3.8 \mathrm{wt} \%$ of $\left.\mathrm{NH}_{3}\right)$. Upgraded anticorrosion efficiency recorded for basic and acidic extracts of phosphate fillers (e.g., zinc phosphate, zinc AP, zinc iron phosphate) in comparison to a neutral extract has been explained in literature by higher water solubility of P-based components at low and high $\mathrm{pH}$ values. ${ }^{24,28}$

\section{Polyurethane paints and coats with phosphate fillers}

Prepared AAPs as well as APs and AZPs were applied as anticorrosion components of solventborne polyurethane paints. The viscosity values of paints (measured at RT) are presented in Fig. 4. In the case of compositions based on AAP, the lowest viscosity was recorded for paints with AAP5 or AAP2 (440 and $460 \mathrm{mPa} \cdot \mathrm{s}$, respectively). These values were only slightly higher in comparison to the viscosity of systems containing microsized phosphates, i.e., PU/AZP $(360 \mathrm{mPa} \cdot \mathrm{s})$ and PU/AP (420 mPa $\mathrm{s})$. Extremely high viscosity was registered for paints filled with nAPs: $700 \mathrm{mPa} \cdot \mathrm{s}$ for PU/nAP-c and $720 \mathrm{mPa} \cdot \mathrm{s}$ for PU/nAP-a. It should be noted that the viscosity values presented did not correlate with the weight/volumetric content of a phosphate filler in paint (Table 2) as well as oil absorption test results (Table 3). The presence of AAP agglomerates in cured coats (detected in AAP/butyl phthalate suspension by using LST) was not confirmed by means of laser scanning microscope (results not presented) due to a large amount of other fillers and pigments in tested coats (Table 2). Nevertheless, the significantly lower viscosity of paints filled with AAPs in comparison to systems containing nanosized aluminium phosphates (PU/nAA-a, PU/nAA-c) might be affected by the size and shape of AAP agglomerates in solventborne coating compositions.

Cured polyurethane coats containing AAP or nanosized nAP exhibited similar or improved adhesion to a steel substrate in comparison to the samples based on commercial phosphates (1.9 MPa for PU/AP and
1.6 MPa for PU/AZP, Fig. 4). The highest adhesion values were observed for coats filled with $\mathrm{nAP}$ (2.5 MPa for PU/nAP-c and $2.4 \mathrm{MPa}$ for PU/nAP-a), AAP3, AAP4, or AAP5 (ca. 2.3 MPa). In the case of systems with nAP fillers, low volumetric phosphate content in coats $(5.1 \mathrm{vol} \%$ of nAP-a, $5.4 \mathrm{vol} \%$ of nAPc, Table 2) and low PVC values (17 for PU/nAP-a and 18.2 for $\mathrm{PU} / \mathrm{nAP}-\mathrm{c})$ resulted in high adhesion to a steel substrate. On the other hand, PU/nAP-a and PU/nAP$\mathrm{c}$ were based on the phosphates exhibiting significantly lower particle size $(270 \mathrm{~nm})$ in comparison to other phosphates (LST results, Table 3). Moreover, the values of analyzed parameters (i.e., low volumetric phosphate content, low PVC, and phosphate particle size) affected the gloss of the mentioned polyurethane coats ( 75 gloss units for PU/nAP-a and 71 gloss units for PU/nAP-c; Fig. 5). A high gloss value for the coat containing AAP3 (60 gloss units) was recorded as well. Probably, it was caused by relatively low agglomerate size/amount of AAP3 $(500 \mathrm{~nm})$ in relation to other AAPs (610-990 nm, 26-35 gloss units) and commercial fillers ( $\leq 4 \mu \mathrm{m}$ and 21 gloss units for PU/AP, $\leq 63 \mu \mathrm{m}$ and 23 gloss units for PU/AZP; Fig. 5). It is generally known that coarse-grained fillers and pigments reduce the gloss of coats. The hardness of cured paints containing APs or AAPs was in the range of 48 to 54 units (Fig. 5) and the highest value of that parameter was noted for PU/AAP5. In the case of PU/AZP, the particle size of AZP was much higher in relation to the APs and other fillers and pigments in the coats. Therefore, the hardness of that coat was very high (71 units).

Observations of delamination around the scribe of polyurethane coats during their exposure in a salt spray chamber for $500,1000,1250$, and $2500 \mathrm{~h}$ are collected in Table 5; blistering observations after $2500 \mathrm{~h}$ of corrosion testing are presented in that table as well. Additionally, digital photos of coated panels exposed for $2500 \mathrm{~h}$ in a salt spray cabinet (and steel bases after coat removal) are shown in Fig. 6. In the case of coats with AAP fillers, the lowest width of delamination area around the scribe $(7.8 \mathrm{~mm})$ and corrosion rate of a steel substrate (after $2500 \mathrm{~h}$ ) were observed for 


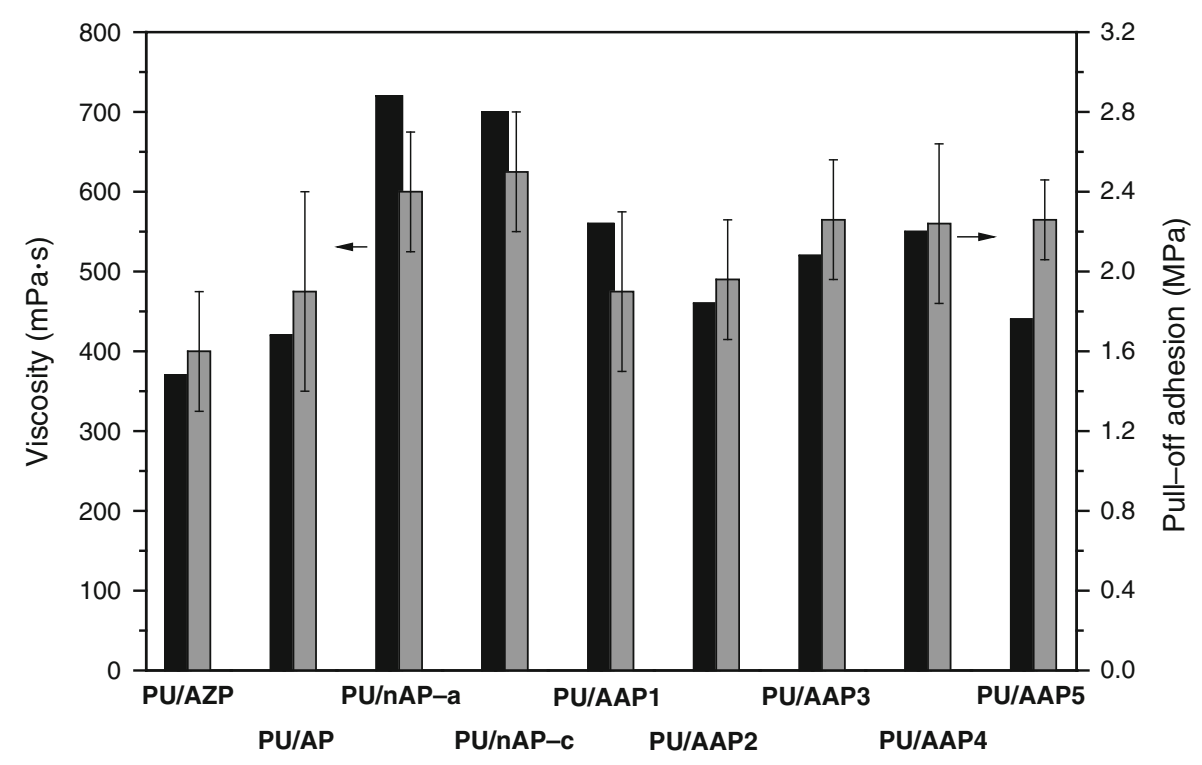

Fig. 4: Viscosity of liquid paints and pull-off adhesion for cured polyurethane coats

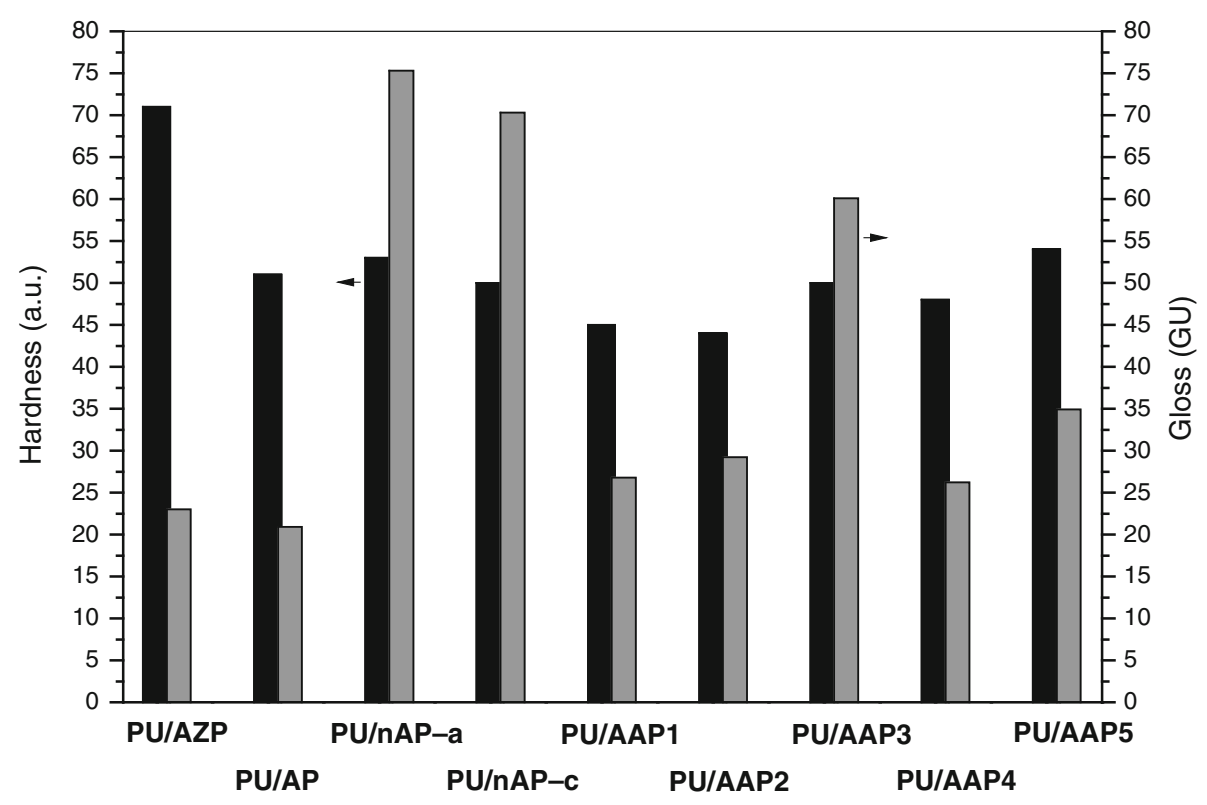

Fig. 5: Hardness and gloss values for cured polyurethane coats

PU/AAP5 sample. Although lower delamination was noted for specimens containing a microsized AP (PU/ AP, $7.3 \mathrm{~mm}$ after $2500 \mathrm{~h}$ ), the coats with AAP5, AAP1, or AAP4 exhibited significantly better anticorrosion characteristics during short-lasting exposure in a salt spray chamber (i.e., $\leq 1250 \mathrm{~h}$ ) than the mentioned coats with AP filler: registered delamination around the scribe was in the range of $3.2 \mathrm{~mm}(500 \mathrm{~h})$ to $5.5 \mathrm{~mm}(1250 \mathrm{~h})$ for PU/AAP5 and $4.8-5.8 \mathrm{~mm}$ for PU/AP, respectively. Blistering outside the scribe (after $2500 \mathrm{~h}$, Table 5) was exclusively noted for PU/ nAP-c and PU/AAP1 samples. Nevertheless, rust traces were not observed on the surface of all coats after a salt spray test.

Generally, the presented delamination results did not correspond to pull-off adhesion values recorded for coats before the salt spray test (Fig. 4). Although the best adhesion to a steel substrate was noted for samples containing nAPs (i.e., PU/nAP-a and PU/nAP-c), these samples exhibited the highest tendency to delamination around the scribe during exposure in a salt spray chamber (Table 5). On the other hand, the lowest delamination value was registered for PU/AP characterized by lower adhesion to steel than PU/nAP-a and PU/nAP-c. 
Table 5: Delamination values and blistering degrees of painted steel panels exposed in a salt spray chamber

\begin{tabular}{|c|c|c|c|c|c|c|c|c|c|}
\hline $\begin{array}{l}\text { Salt spray test } \\
\text { duration (h) }\end{array}$ & PU/AZP & PU/AP & PU/nAP-a & PU/nAP-c & PU/AAP1 & PU/AAP2 & PU/AAP3 & PU/AAP4 & PU/AAP5 \\
\hline \multicolumn{10}{|c|}{ Delamination around the scribe ${ }^{\mathrm{a}}(\mathrm{mm})$} \\
\hline 500 & 0 & $4.8 \pm 1.4$ & $4.7 \pm 2.1$ & $5.4 \pm 1.7$ & $3.3 \pm 1.2$ & $3.6 \pm 1.3$ & $3.1 \pm 1.5$ & $2.5 \pm 1.0$ & $3.2 \pm 1.7$ \\
\hline 1000 & $5.0 \pm 2.9$ & $5.1 \pm 1.6$ & $8.8 \pm 3.2$ & $11.3 \pm 3.0$ & $3.9 \pm 1.7$ & $5.5 \pm 2.2$ & $8.7 \pm 2.7$ & $3.4 \pm 1.2$ & $5.0 \pm 1.9$ \\
\hline 1250 & $5.7 \pm 3.8$ & $5.8 \pm 1.8$ & $9.5 \pm 2.9$ & $13.5 \pm 4.7$ & $4.5 \pm 1.8$ & $5.8 \pm 2.3$ & $9.6 \pm 1.9$ & $4.2 \pm 1.0$ & $5.5 \pm 1.7$ \\
\hline 2500 & $9.4 \pm 4.1$ & $7.3 \pm 2.8$ & $14.5 \pm 2.8$ & $14.2 \pm 2.8$ & $10.5 \pm 1.3$ & $10.8 \pm 1.8$ & $11.1 \pm 2.8$ & $9.5 \pm 1.6$ & $7.8 \pm 2.7$ \\
\hline \multicolumn{10}{|c|}{ Blistering outside the scribe ${ }^{b}$} \\
\hline 2500 & $0(0)$ & $0(0)$ & $0(0)$ & 5 (s4) & 5 (s5) & $0(0)$ & $0(0)$ & $0(0)$ & $0(0)$ \\
\hline
\end{tabular}

a According to EN ISO 4628-8

b Described as "frequency(size)" of blisters according to EN ISO 4628-2

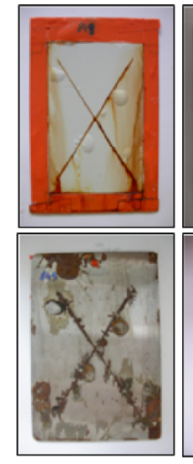

PU/AZP

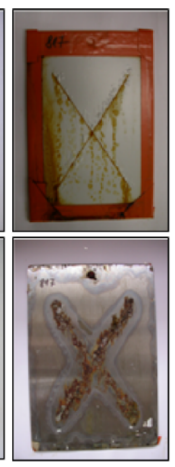

PU/AP

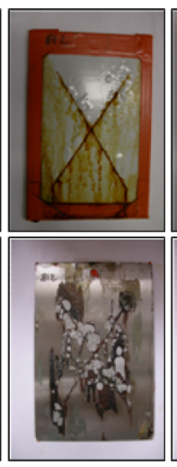

PU/nAP-a

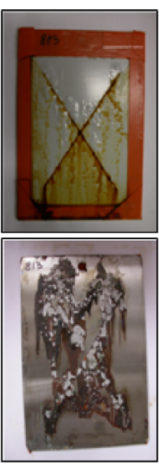

PU/nAP-c

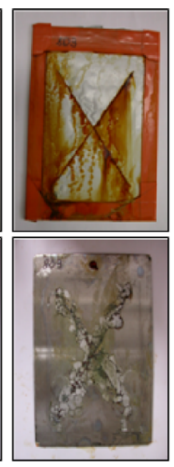

PU/AAP1

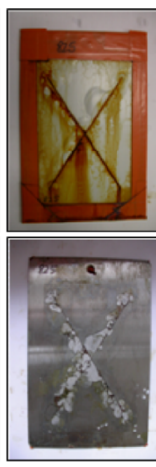

PU/AAP2
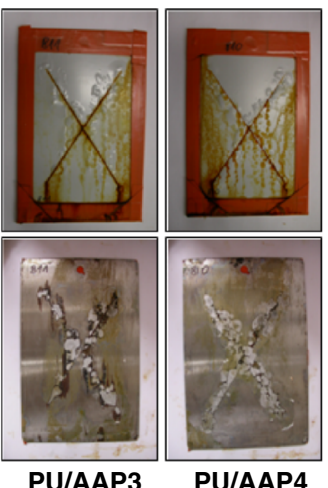

PU/AAP4

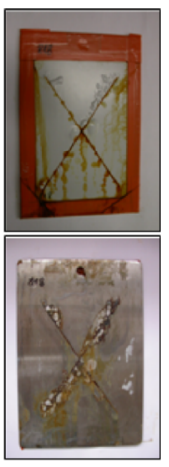

PU/AAP5

Fig. 6: The macrographs of coated steel samples (top) and steel samples with removed coats (bottom) after exposure for $2500 \mathrm{~h}$ in a salt spray chamber

For coats containing AAP fillers, it can be claimed that the lowest delamination around the scribe (after $500 \mathrm{~h}$ ) was registered for the samples exhibiting better adhesion to a steel substrate (PU/AAP3, PU/AAP4, PU/AAP5; Fig. 4). That relation was not observed after $2500 \mathrm{~h}$ of salt spray test. In that case the highest anticorrosion properties were registered for samples with AAP containing a similar/low amount of $\mathrm{NH}_{3}$ (i.e., AAP5 and AAP4, $3.3 \mathrm{wt} \%$, Table 3) and characterized by a low $\left(\mathrm{Al}+\mathrm{NH}_{3}\right) / \mathrm{PO}_{4}{ }^{3-}$ molar content ratio (1.78 for AAP5 and 1.88 for AAP4, Fig. 7). Additionally, the values of the total surface of phosphate particles (located in $100 \mathrm{~cm}^{3}$ of cured coat) were higher for PU/AAP5 and PU/AAP4 (3633 and $3023 \mathrm{~m}^{2}$, respectively; Fig. 7) than for samples with other AAP and nAP fillers. For PU/AZP and PU/AP samples, the mentioned parameter values were significantly low (147.4 and $91.4 \mathrm{~m}^{2} / 100 \mathrm{~cm}^{3}$, respectively) but these coats contained higher amounts of anticorrosion fillers (i.e., $7.7 \mathrm{vol} \%$ of PU/AZP and $7.6 \mathrm{vol} \%$ of PU/AP) in comparison to other systems (5.1-7.1 vol\% of phosphate; Table 2). Anticorrosion efficiency of PU/AZP and PU/AP was also improved by the higher water solubility of AZP and AP in relation to $\mathrm{AAP}$ and AAP fillers (Table 3).
Electrical parameters calculated on the basis of EIS data are presented in Fig. $8\left(R_{\mathrm{pr}}\right)$, Fig. $9\left(C_{\mathrm{cr}}\right)$, and Fig. $10\left(R_{\mathrm{fr}}\right)$. It is known that $R_{\mathrm{pr}}$ and $C_{\mathrm{cr}}$ parameters generally represent the barrier properties of coats while $R_{\mathrm{fr}}$ characterizes coat-metal interface. As can be seen, the highest relative pore resistance (after 500, 1000 , and $2500 \mathrm{~h}$ of immersion in saline water) was registered for coats containing AZP, nAP-c, AAP3, or nAP-a. Probably, it was affected by the low electrical conductivity of aqueous extracts of these phosphates $(24-631 \mu \mathrm{S} / \mathrm{cm})$ in relation to other extracts $(1520$ $2169 \mu \mathrm{S} / \mathrm{cm}$, Table 3) and/or by the absence of phosphate agglomerates in the mentioned coats. During water permeation into the coat, the aqueous extract of phosphate filler was created and its conductivity influenced $R_{\mathrm{pr}}$ values. On the other hand, a coat without voids (e.g., air inside filler agglomerates) cannot be easily penetrated by water. Considering SEM images of nAP-a and AAP5 (Fig. 2) as well as the results of particle size analysis, $S_{\mathrm{BET}}$, and oil absorption values (Table 3), it can be suggested that PU/ AAP3 did not contain phosphate agglomerates. Therefore, PU/AAP3 exhibited significantly higher $R_{\mathrm{pr}}$ than the samples with other AAPs (i.e., PU/AAP1, PU/ AAP2, PU/AAP4, or PU/AAP5, Fig. 8). The 


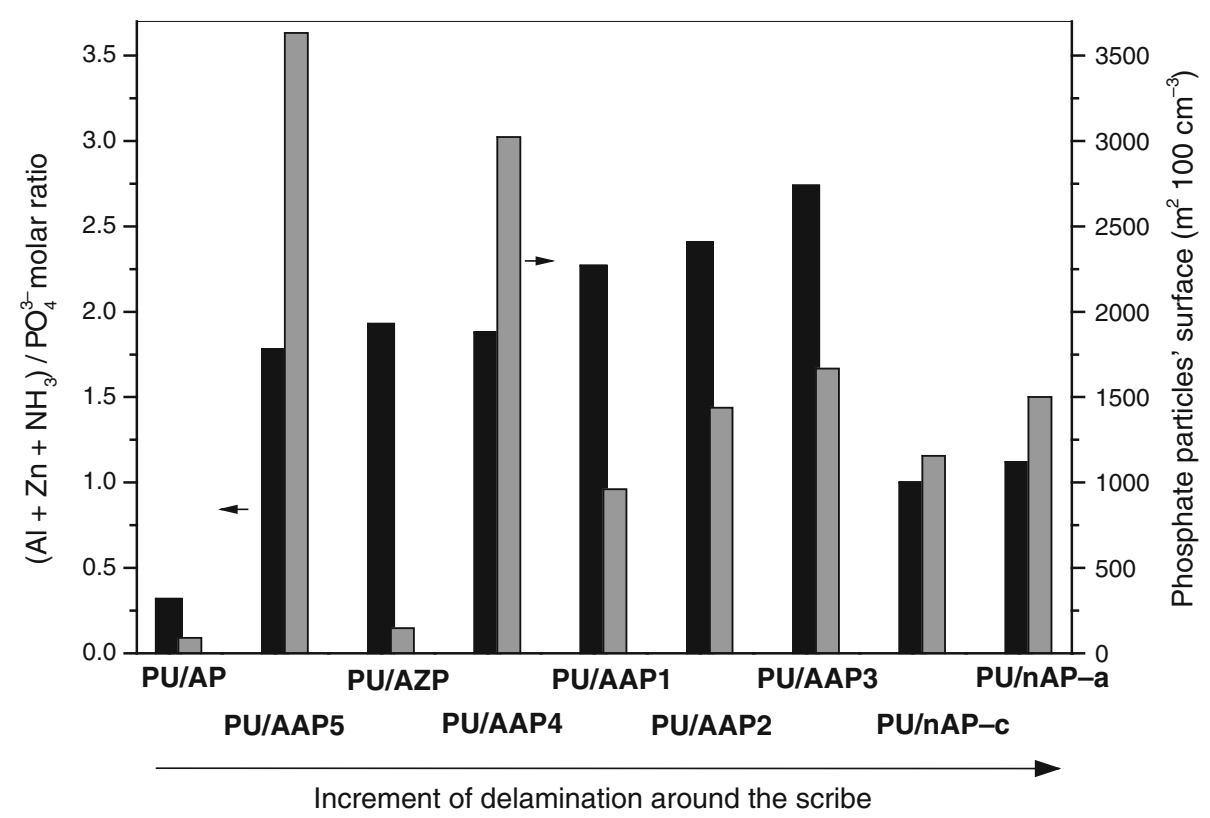

Fig. 7: The relation of delamination around the scribe (after $2500 \mathrm{~h}$ of coats exposure in a salt spray chamber) to $\left(\mathrm{Al}+\mathrm{Zn}+\mathrm{NH}_{3}\right) / \mathrm{PO}_{4}{ }^{3-}$ molar ratio of phosphate fillers and total surface of phosphate particles in cured paints

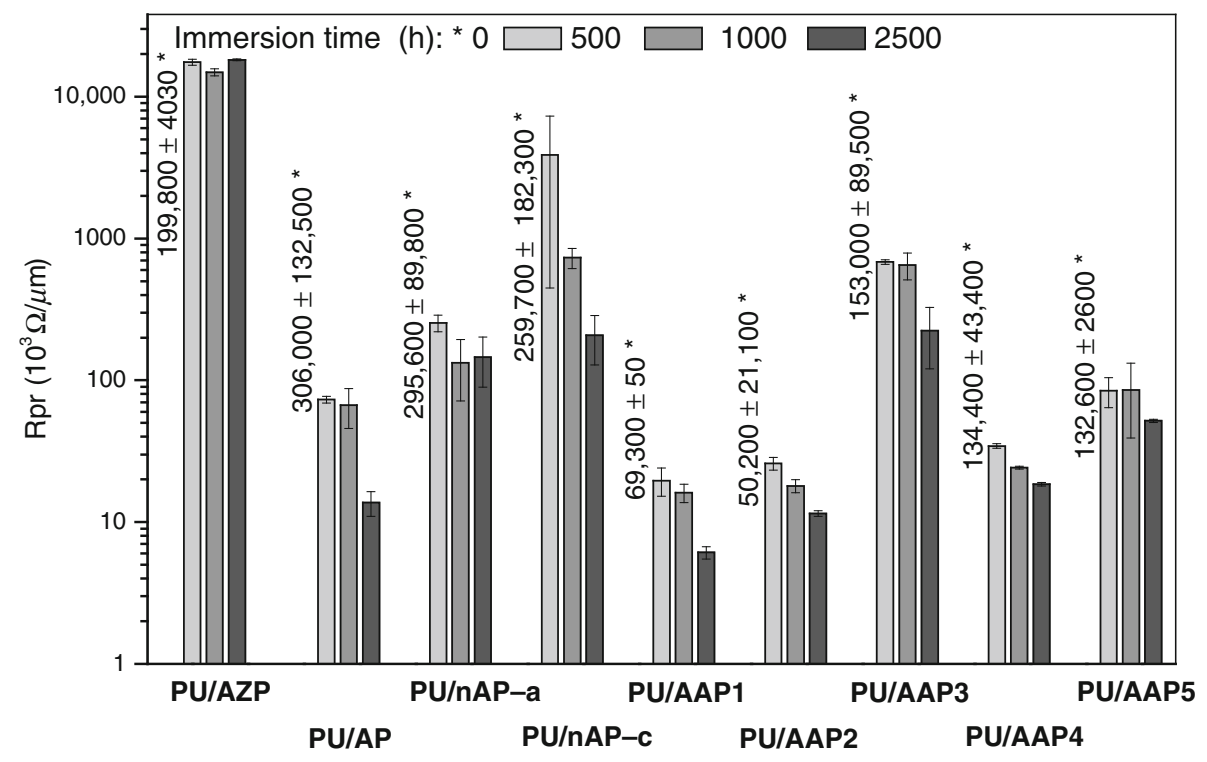

Fig. 8: Relative pore resistance $\left(\boldsymbol{R}_{\mathrm{pr}}\right)$ variation of coats during immersion in an aqueous $\mathrm{NaCl}$ solution

presented thesis was confirmed by relatively lower $C_{\mathrm{cr}}$ values noted for PU/AAP3 (and coats with nAP fillers) in comparison to the samples with AAP1, AAP2, AAP4. or AAP5 (Fig. 9). It should be noted that the most reduced $C_{\mathrm{cr}}$ was recorded for the coats with nAPs (nAP-a, nAP-c). Moreover, PU/AP did not (probably) contain phosphate agglomerates; thus, the low $R_{\mathrm{pr}}$ of that coat was a result of high conductivity of AP extract (Table 3).

The relative polarization resistance $\left(R_{\mathrm{fr}}\right)$ values for coats with APs and AAPs correlated with the Tafel test results obtained for steel in neutral extracts. Due to the high barrier/anticorrosion properties of PU/AZP, the mentioned parameter $\left(R_{\mathrm{fr}}\right)$ was not measured for that sample (the second time constant characteristic was not revealed during EIS test). As can be observed in Fig. 10, the highest $R_{\mathrm{fr}}$ values were noted for coats containing nAP-a, nAP-c, AAP3, or AAP5. Neutral extracts of these phosphates exhibited the highest corrosion inhibition efficiency (Table 4). Probably, during immersion of coated samples in saline water, the electrolyte reached a coat-steel interface and an 


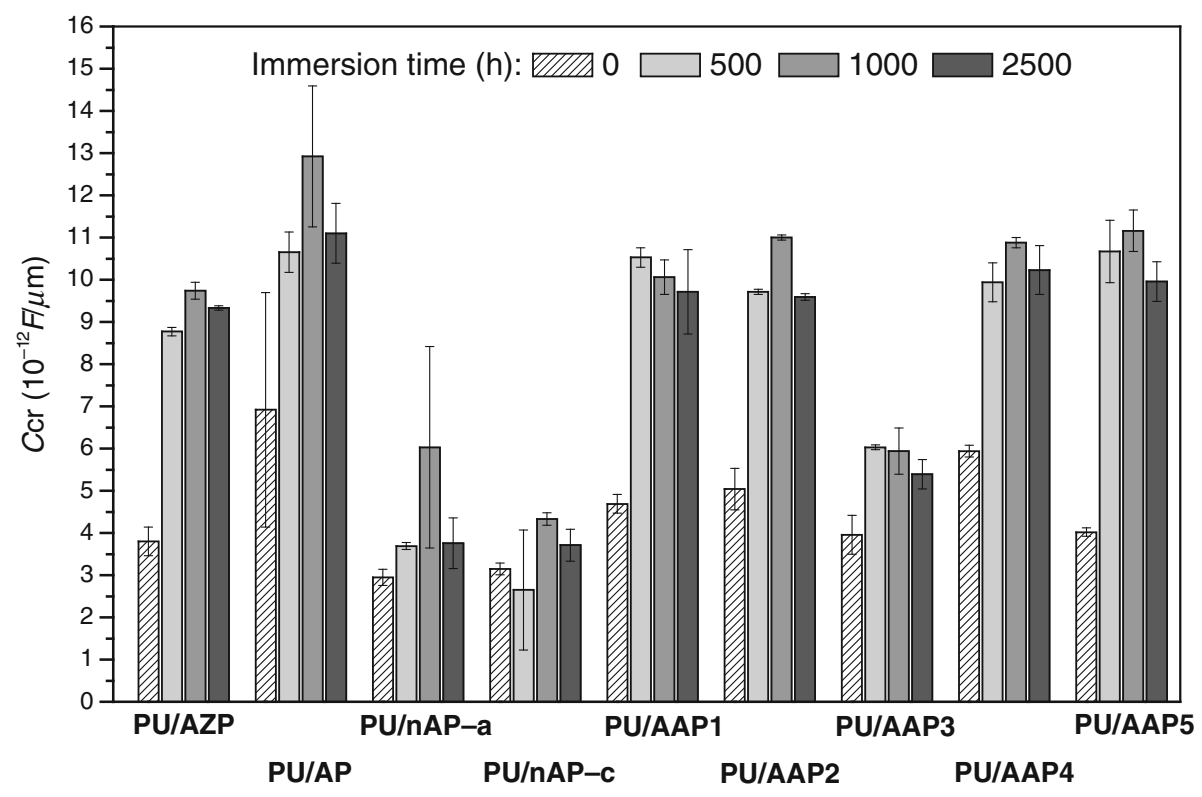

Fig. 9: Relative coat capacitance $\left(C_{\mathrm{cr}}\right)$ variation of coats during immersion in an aqueous $\mathrm{NaCl}$ solution

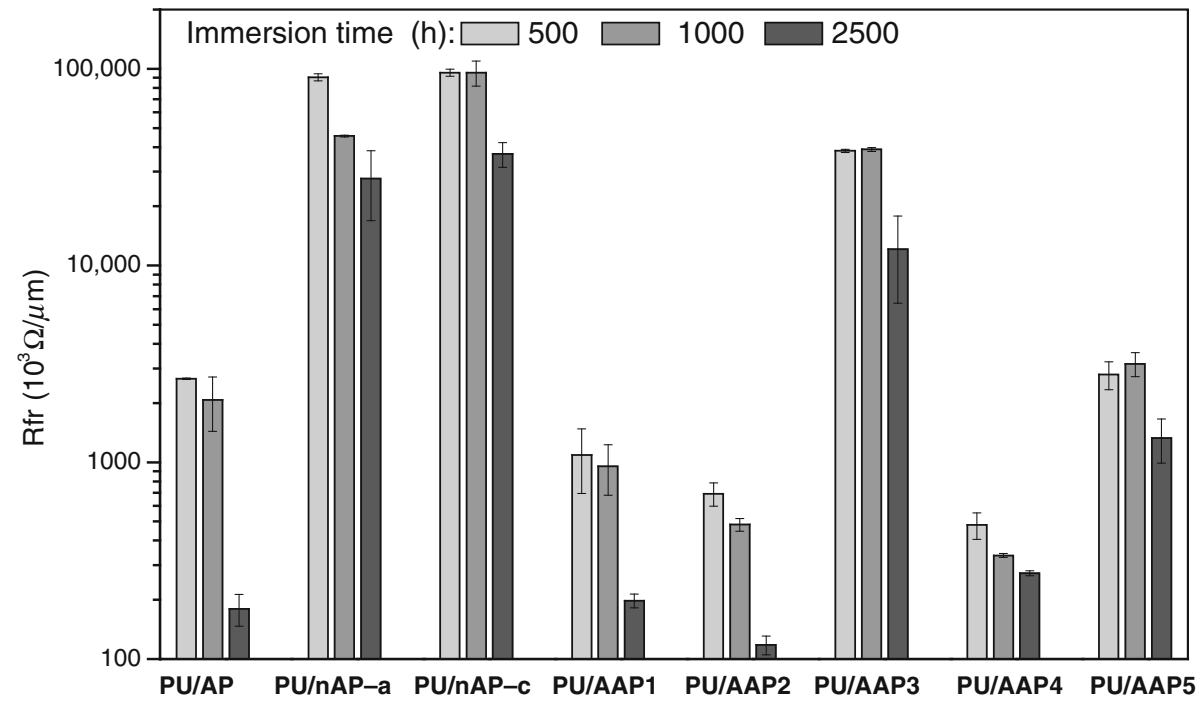

Fig. 10: Relative polarization resistance $\left(\boldsymbol{R}_{\mathrm{fr}}\right)$ variation of coats during immersion in an aqueous $\mathrm{NaCl}$ solution

undercoat rusting process was subsequently initiated. During the initial stage of that process (neutral $\mathrm{pH}$ of electrolyte), phosphate-based corrosion products were precipitated and covered the metallic substrate; thus, high $R_{\text {fr }}$ values were detected. That phenomenon for coats with phosphate fillers has been presented in literature. $^{29}$ It should be noted that $R_{\text {fr }}$ recorded for PU/nAP-a, PU/nAP-c, PU/AAP3, and PU/AAP5 coats was relatively stable during the immersion test. In the case of PU/AP, PU/AAP1, and PU/AAP2, parameter values were markedly reduced after $2500 \mathrm{~h}$ of immersion. In fact, the corrosion rate for steel immersed in extracts of these fillers was very high (Table 4).
Generally, EIS data and the Tafel test results (for steel tested in neutral extracts of phosphates) did not correlate with the observation of coated samples exposed in a salt spray chamber. Only in the case of PU/AZP were good anticorrosion properties during salt spray test (i.e., limited delamination around the scribe and a low amount of corrosion products on steel surface, Fig. 6), as well as relatively high values of $R_{\mathrm{pr}}$ (Fig. 8) and $\eta$ (neutral pH, Table 4), simultaneously revealed. On the other hand, it can be claimed that the results of potentiodynamic steel polarization in basic extracts of AAPs corresponded to the salt spray test results recorded for coats with these phosphates; the 
highest corrosion inhibition efficiency was noted for AAP5 and AAP4 fillers while the lowest $\eta$ was calculated for AAP2 and AAP3 (Table 4). Therefore, PU/AAP5 and PU/AAP4 coats exhibited markedly lower delamination around the scribe $(2500 \mathrm{~h}$, Table 5) than PU/AAP2 and PU/AAP3. Moreover, coats with AAP5 (delamination $7.8 \mathrm{~mm}, \eta=74 \%$ ) offered better steel protection in comparison to the system containing AZP (9.4 mm, 1\%).

Considering the results of potentiodynamic steel polarization in phosphate extracts, as well as EIS and salt spray test results for polyurethane coats containing phosphate fillers, it can be found that AAP5 offered the best barrier/anticorrosion features (i.e., high corrosion inhibition efficiency of basic extract of the filler, high $R_{\mathrm{pr}}$ and low delamination of polyurethane coats around the scribe, and reduction of undercoat corrosion processes during the exposure in a salt spray cabinet) in comparison to other AAPs, micro- and nAPs as well as to AZP. Moreover, AAP5 did not contain zinc, so it can be called a really environmentally friendly anticorrosion filler.

\section{Conclusions}

Novel AAPs, prepared via the simple reaction of aluminum sulfate and ammonium phosphate in an aqueous medium, can be used as effective $\mathrm{Zn}$-free anticorrosion fillers in $2 \mathrm{~K}$ polyurethane paints. Taking into consideration the test results of solventborne paints and cured coats containing AZP, APs (microand nanosized), or AAPs, the following conclusions can be drawn:

- Coating compositions containing AAP exhibited similar (AAP2, AAP5) or slightly higher viscosity than paints based on microsized AZP and AP fillers at the same $\Lambda$ parameter value;

- An incorporation of AAP into polyurethane paint improved adhesion of cured coats to a steel substrate (AAP3, AAP4, AAP5), their hardness (AAP5), and gloss (AAP3 and AAP5) in comparison to the systems filled with AZP or AP;

- Coating composition with AAP (AAP5, $10 \mathrm{wt} \%$ ) exhibited similar or reduced delamination around the scribe and blistering resistance (after $2500 \mathrm{~h}$ in a salt spray chamber) in relation to the coats containing $13.7 \mathrm{wt} \%$ of commercial microsized AP or $15.6 \mathrm{wt} \%$ of AZP. In the case of short-lasting tests $(\leq 1250 \mathrm{~h})$, coats containing AAP1, AAP4, or AAP5 achieved better anticorrosion features than samples with the mentioned AP filler;

- EIS test results showed markedly higher barrier properties of the PU/AAP5 coat in comparison to the sample with microsized AP. The corrosion rate of steel immersed in a neutral extract of AAP5 was markedly lower than in neutral extract of microsized AP. In the case of alkaline extracts of the phosphates, AAP5 offered higher corrosion inhibition efficiency in comparison to APs (micro- and nanosized) and AZP.

Acknowledgments This work was supported by the National Centre for Science in Poland under project. The authors thank Ms. Birte Grätzer (Worlée-Chemie $\mathrm{GmbH}$ ) for supplying the binder for coating compositions.

Open Access This article is distributed under the terms of the Creative Commons Attribution License which permits any use, distribution, and reproduction in any medium, provided the original author(s) and the source are credited.

\section{References}

1. Deyá, C, Blustein, G, del Amo, B, Romagnoli, R, "Evaluation of Eco-friendly Anticorrosive Pigments for Paints in Service Conditions." Prog. Org. Coat., 69 1-6 (2010)

2. Hamdy, A, "A Clean Low Cost Anti-corrosion Molybdate Based Nano-particles Coating for Aluminum Alloys." Prog. Org. Coat., 56 146-150 (2006)

3. Spychaj, T, Spychaj, S, Water-Thinnable Paints and Adhesives. WNT, Warsaw, 1996

4. Kalendova, A, Kalenda, P, Veselý, D, "Comparison of the Efficiency of Inorganic Nonmetal Pigments with Zinc Powder in Anticorrosion Paints." Prog. Org. Coat., 57 1-10 (2006)

5. Śmieszek, E, Kamińska, E, Ochrona Przed Korozją (Corros Protect), 4 85-88 (1996)

6. Abd El-Ghaffar, M, Youssef, E, Ahmed, N, "High Performance Anticorrosive Paint Formulations Based on Phosphate Pigments." Pigment. Resin. Technol., 33 226-237 (2004)

7. Blustein, G, Dayá, M, Romagnoli, R, del Amo, B, “Three Generations of Inorganic Phosphates in Solvent and WaterBorne Paints: A Synergism Case."' Appl. Surf. Sci., 252 13861397 (2005)

8. Kalendova, A, Veselý, D, Kalenda, P, "A Study of the Effects of Pigments and Fillers on the Properties of Anticorrosive Paints." Pigment. Resin. Technol., 35 83-94 (2006)

9. Naderi, R, Attar, M, "Electrochemical Assessing Corrosion Inhibiting Effects of Zinc Aluminum Polyphosphate (ZAPP) as a Modified Zinc Phosphate Pigment." Electrochim. Acta, $535692-5696$ (2008)

10. de Lima-Neto, P, de Araújo, A, Araújo, W, Correia, A, "Study of the Anticorrosive Behaviour of Epoxy Binders Containing Non-toxic Inorganic Corrosion Inhibitor Pigments." Prog. Org. Coat., 62 344-350 (2008)

11. del Amo, B, Romagnoli, R, Deyá, C, González, J, "High Performance Water-Based Paints with Non-toxic Anticorrosive Pigments." Prog. Org. Coat., 45 389-397 (2002)

12. Galliano, F, Landolt, D, "Evaluation of Corrosion Protection Properties of Additives for Waterborne Epoxy Coatings on Steel." Prog. Org. Coat., 44 217-225 (2002) 
13. Hernández, M, Genescá, J, Uruchurtu, J, Galliano, F, Landolt, D, "Effect of an Inhibitive Pigment Zinc-Aluminum-Phosphate (ZAP) on the Corrosion Mechanisms of Steel in Waterborne Coatings." Prog. Org. Coat., 56 199-206 (2006)

14. Naderi, R, Attar, M, "The Role of Zinc Aluminum Phosphate Anticorrosive Pigment in Protective Performance and Cathodic Disbondment of Epoxy Coating." Corros. Sci., 52 1291-1296 (2010)

15. Naderi, R, Attar, M, "Electrochemical Study of Protective Behavior of Organic Coating Pigmented with Zinc Aluminum Polyphosphate as a Modified Zinc Phosphate at Different Pigment Volume Concentrations." Prog. Org. Coat., 66 314-320 (2009)

16. Kowalczyk, K, Łuczka, K, Grzmil, B, Spychaj, T, "Anticorrosive Polyurethane Paints with Nano- and Microsized Phosphates." Prog. Org. Coat., 74 151-157 (2012)

17. Kowalczyk, K, Łuczka, K, Grzmil, B, Spychaj, T, "Anticorrosive 2K Polyurethane Paints Based on Nano- and Microphosphates with High Dispersing Additive Content." Prog. Org. Coat., 76 1088-1094 (2013)

18. Gawri, S, Balakrishnan, K, "The Effect of the PVC/CPVC Ratio on the Corrosion Resistance Properties of Organic Coatings." Prog. Org. Coat., 23 363-377 (1994)

19. Minczewski, J, Marczenko, Z, Analytical Chemistry (Part 2). PWN, Warsaw, 2005
20. Orion Ammonia Electrode, Instruction manual, Thermo Electron Corporation, 2003

21. Murray, J, "Electrochemical Test Methods for Evaluating Organic Coatings on Metals: An Update. Part III: Multiple Test Parameter Measurements.” Prog. Org. Coat., 31 375-391 (1997)

22. Kic, B, Grzmil, B, Lubkowski, K, "Preparation of Nanocrystalline Aluminium Phosphate as an Anticorrosive Pigment." Przem. Chem., 88 468-471 (2009)

23. Pourbaix, M, Leçons en Corrosion Electrochimique. PWN, Warsaw, 1978

24. Bethencourt, M, Botana, F, Marcos, M, Osuna, R, SanchezAmaya, J, "Inhibitor Properties of "Green" Pigments for Paints.” Prog. Org. Coat., 46 280-287 (2003)

25. Jaskova, V, Kalendova, A, "Anticorrosive Coatings Containing Modified Phosphates.” Prog. Org. Coat., 75 328-334 (2012)

26. Amirudin, A, Barreau, C, Hellouin, R, Thierry, D, "Evaluation of Anti-corrosive Pigments by Pigment Extract Studies, Atmospheric Exposure and Electrochemical Impedance Spectroscopy." Prog. Org. Coat., 25 339-355 (1995)

27. Uhlig, H, Corrosion and Corrosion Control. WNT, Warsaw, 1976

28. Hernandez, M, Galliano, F, Landolt, F, "Mechanism of Cathodic Delamination Control of Zinc-Aluminum Phosphate Pigment in Waterborne Coatings." Corros. Sci., 46 2280-2300 (2004)

29. Hao, Y, Liu, F, Han, E-H, Anjum, S, Xu, G, "The Mechanism of Inhibition by Zinc Phosphate in an Epoxy Coating." Corros. Sci., 69 77-86 (2013) 